\title{
Peran kader Ranting 'Aisyiyah Cabang Kota Yogyakarta dalam pemberdayaan masyarakat di bidang kesehatan
}

\author{
Ririn Wahyu Hidayati, ${ }^{1 *}$ Nurul Mahmudah ${ }^{2}$ \\ ${ }^{1,2}$ Program Studi Kebidanan Program Sarjana Terapan, Universiyas Aisyiyah Yogyakarta - \\ Indonesia
}

\begin{abstract}
Health cadres have a role to assist the government in improving community health status, reducing MMR and IMR. One of his roles is to become a Posyandu cadre in Aisyiyah. But in reality, cadres have a dual role. Therefore, the researcher intends to find out how far the participation of Health cadres is in Branch Aisyiyah, Yogyakarta City Branch. This research is a qualitative study and was conducted at the Branch of 'Aisyiyah Yogyakarta City Branch in 2017. The number of participants was taken to have a saturated answer from the cadre of isy Aisyiyah. Test analysis with content analysis. The results obtained that the cadres 'Aisyiyah collaborated with educational institutions both 'Aisyiyah or Muhammadiyah to provide health education, health checks and treatment. Health related activities are carried out both in the activities of recitation, social gathering, study or routine meetings of warga Aisyiyah residents. Other programs that are running are TB Knocking, assistance in taking medicine, Posyandu Elderly Sakinah, and early detection of non-communicable diseases. "Aisyiyah cadres play a role in mutual cooperation" from, for and by the community ". The number of cadres and the age of keder 'Aisyiyah is not a barrier to their performance. Complementarity and cooperation are the keys to the implementation of work programs in accordance with the aim of improving the level of public health. Young cadres as implementers, senior cadres as advisors. Based on the results of the study it can be concluded that Aisyiyah cadres play an active role to improve public health despite having a dual role.
\end{abstract}

Keywords: role of cadres; community empowerment

\begin{abstract}
Kader kesehatan berperan membantu pemerintah dalam meningkatkan derajat kesehatan masyarakat, menurunkan AKI dan AKB. Salah satu perannya adalah menjadi kader Posyandu di Aisyiyah. Namun pada kenyataannya kader memiliki peran ganda. peneliti bermaksud mengetahui seberapa jauh peran serta kader Kesehatan di Ranting 'Aisyiyah Cabang Kota Yogyakarta. Penelitian ini merupakan penelitian kualitatif dan dilakukan di Ranting 'Aisyiyah Cabang Kota Yogyakarta tahun 2017. Jumlah partisipan diambil hingga memiliki jawaban yang jenuh dari kader 'Aisyiyah. Uji analisis dengan content analysis. Hasil penelitian diperoleh bahwa Kader 'Aisyiyah melakukan kerjasama dengan Institusi pendidikan baik 'Aisyiyah atau Muhammadiyah untuk memberikan penyuluhan kesehatan, pemeriksaan kesehatan dan pengobatan. Kegiatan terkait kesehatan dilakukan baik dalam kegiatan pengajian, arisan, kajian atau pertemuan rutin warga 'Aisyiyah. Program lain yang berjalan yaitu Ketuk Pintu TB, pendampingan minum obat, Posyandu Lansia Sakinah, dan deteksi dini Penyakit Tidak Menular. Kader 'Aisyiyah berperan dengan cara gotong royong "dari, untuk dan oleh masayrakat". Jumlah kader dan usia keder 'Aisyiyah bukan sebagai penghalang kinerja mereka. Saling melengkapi dan kerjasama adalah kunci terlaksananya program kerja yang sesuai dengan tujuan meningkatkan taraf kesehatan masyarakat.
\end{abstract}

"Korespondensi Penulis: Ririn Wahyu Hidayati (email: ririnwahyu22@gmail.com), Jl. Ringroad Barat No. 63, Mlangi Nogotirto. Gamping, Kabupaten Sleman, Daerah Istimewa Yogyakarta 55592. 
Kader muda sebagai pelaksana, kader senior sebagai penasihat. Berdasarkan hasil penelitian dapat disimpulkan bahwa kader Aisyiyah berperan aktif untuk meningkatkan kesehatan masyarakt walaupun memiliki peran ganda.

Kata Kunci: peran kader; pemberdayaan masyarakat

\section{Pendahuluan}

Masalah kader kesehatan menyita perhatian dalam beberapa tahun terakhir. Hal ini dikarenakan banyak program kesehatan dunia menekankan potensi kader kesehatan untuk meningkatkan derajat kesehatan pada masyarakat. Kader kesehatan masyarakat adalah titik awal perawatan yang bekerja pada tingkat rumah tangga seperti pengelolaan gizi, promosi kesehatan ibu dan anak, imunisasi, pengendalian penyakit menular dan pelaksanaan intervensi penyakit menular (Rachmat, 2017). Kader kesehatan masyarakat sebagai garis depan bagi masyarakat yang anggotanya terpercaya dan atau memiliki pemahaman yang lebih mengenai kesehatan.

Peran kader kesehatan masyarakat yang terpenting adalah menciptakan kondisi agar masyarakat dapat meningkatkan kesehatan bagi masyarakat itu sendiri, keluarga dan masyarakat sekitar, sebagai anggota masyarakat yang dipercaya dan memahami kesehatan (Sulaeman, 2012). Guna meningkatkan kesehatan masyarakat maka kader berperan aktif untuk membentuk kesadaran masyarakat agar dapat meningkatkan kualitas hidupnya. Kader memberikan motivasi, memberikan contoh hingga menjalankan program untuk meningkatkan kesehatan (Effendi \& Makhfudli, 2009). Salah satu bentuk peran kader di Aisyiyah adalah menjadi pelopor gerakan hidup sehat, menjadi pengurus Ranting 'Aisyiyah dan dapat menyampaikan informasi kesehatan yang diperolehnya kepada masyarakat. Kader juga bertanggung jawab dalam pelaksanaan program Posyandu. Selain itu kader juga aktif dalam bidang agama sehingga ada keseimbangan. Guna mendukung berjalannya program pemerintah tersebut, organisasi Islam seperti Aisyiyah pun berjalan di bidang kesehatan. Tugasnya pun tidak jauh beda dengan tugas kader dari Posyandu bahkan ada pula keder yang dibentuk dari orang-orang 'Aisyiyah. Khususnya di Kota Yogyakarta dengan kepadatan penduduk yang paling tinggi (Bappeda, 2013) maka memerlukan peran dari kader masyarakat untuk menurunkan angka kematian dan kesakitan. Program yang dikembangkan untuk meningkatkan kesehatan antara lain pendamping TB, Screaning TB, pemeriksaan Stunting, pencegahan penyakit tidak menular (PTM) (Dinkes DIY, n.d.). Kegiatan tersebut dijalankan dengan kerjasama dengan Perguruan tinggi Swasta.

Meskipun Posyandu sangat diperlukan dan penting peranannya bagi pemerintah, namun kenyataannya secara nasional hanya $27,3 \%$ rumah tangga yang telah memanfaatkannya. Sebanyak $62,5 \%$ rumah tangga tidak membutuhkan, dan 10,2\% rumah tangga tidak menggunakan fasilitas Posyandu untuk alasan lainnya (Iswarawanti, 2010). Mengingat masih kurangnya pemanfaatan layanan kesehatan di masyarakat seperti Posyandu, maka peneliti perlu meninjau kembali peran serta kader 'Aisyiyah yang berada 
di wilayah Ranting 'Aisyiyah Cabang Kota Yogyakarta.

\section{Metode Penelitian}

Penelitian ini menggunakan metode penelitian kualitatif dengan desain penelitian deskriptif fenomenologi (Hidayat, 2002) untuk menggali secara mendalam peran serta kader kesehatan dalam pemberdayaan masyarakat di tingkat Ranting 'Aisyiyah Yogyakarta. Jumlah populasi kader kesehatan di Ranting 'Aisyiyah sebanyak 21 orang. Pengambilan sampel dengan tehnik snow ball sampling (Sugiyono, 2012) sehingga diperoleh 10 partisipan. Pengambilan data dilakukan dengan wawancara mendalam dan hasil wawancara dilakukan analisis hasil wawancara. Penelitian dilakukan selama 1 bulan.

\section{Hasil dan Pembahasan}

Pemberdayaan masyarakat adalah suatu upaya atau proses untuk menumbuhkan kesadaran, kemauan dan kemampuan masyarakat dalam mengenali, mengatasi, memelihara, melindungi dan meningkatkan kesejahteraan mereka sendiri (Syafrudin \& Hamidah, 2009). Pemberdayaan masyarakat bidang kesehatan adalah upaya atau proses untuk menumbuhkan kesadaran kemauan dan kemampuan dalam memelihara dan meningkatkan kesehatan (Supardan, 2013). Hal ini dapat terwujud dari salah satu peran dan fungsi dari kader kesehatan di Wilayah Ranting 'Aisyiyah. Kepedulian kader untuk membantu masyarakat meningkatkan taraf kesehatannya melalui kerja sama lintas sektor dan lintas program.
Bidang pembangunan biasanya meliputi 3 (tiga) sektor utama, yaitu ekonomi, sosial (termasuk di dalamnya bidang pendidikan, kesehatan dan sosial-budaya), dan bidang lingkungan. Pemberdayaan dalam wacana pembangunan selalu dihubungkan dengan konsep mandiri, partisipasi, jaringankerja, dan keadilan. Pada dasarnya, pemberdayaan diletakkan pada kekuatan tingkat individu dan sosial (Depkes RI, 2008).

Kader di Ranting 'Aisyiyah merupakan warga masyarakat yang dianggap penting (Meilani, 2009), dipilih oleh masyarakat sendiri dan mampu menjalankan tugas secara suarela demi kebaikan bersama (Fallen \& Dwi, 2011). Berdasarkan hasil wawancara untuk kader bidang kesehatan diperoleh data sebagia berikut. Kader 'Aisyiyah Umbulharjo berasal dari orang-orang Muhammadiyah atau ibu-ibu 'Aisiyah. Rata-rata kader merupakan seorang ibu, ada yang bekerja menjadi guru, ibu rumah tangga dan bahkan sudah menjadi nenek. Sedangkan kader muda atau remaja belum banyak yang ikut dalam kegiatan rutin 'Aisyiyah. Remaja lebih banyak dalam kegiatan umum kemasyarakatan (desa), menjadi remaja Masjid atau pemuda desa. Tidak jauh berbeda dari Umbulharjo, bahwa Ranting 'Aisyiyah Tegalrejo juga memiliki kader yang berperan ganda. Kader juga seorang ibu yang memiliki pekerjaan lain. Namun, ada pula kader yang aktif dalam kegiatan Ranting Tegalrejo namun tidak tinggal di Tegalrejo. Yang artinya beliau seharihari aktif di kegiatan organisasi yang berada di Tegalrejo. Ada pula ibu-ibu rumah tangga yang memiliki kesibukan membuka toko di wilayah Tegalrejo. Kader dari Ranting 'Aisyiyah Jetis saat ini sudah 3 periode belum ganti kepengurusan. 
Proses kaderisasi masih terus berlangsung, dan pernah dilakukan pendampingan kader muda namun belum berjalan maksimal. Oleh karena itu kader lamalah yang tetap menjalankan semua kegiatan organisasi. Jumlah kader terdapat sekitar 10 orang secara administratif, namun yang aktif dalam kegiatan hanya sekitra 4-5 orang saja. Kader tersebut merupakan pengurus inti Ranting 'Aisiyah dan merupakan ketua RT, ketua RW, dan 3 kader Posyandu. Ranting 'Aisyiyah Kotagede memiliki pengurus Ranting yang aktif. Namun ada pula yang tidak aktif. Pengurus aktif akan merangkap beberapa kegiatan. Seperti ketua Ranting, menjadi pula ketua RT, atau kader Posyandu dan juga menjadi anggota majelis taklim yang lain.

Kader 'Aisyiyah tersebut tidak hanya sematamata menjadi bagian dari organisasi namun juga meraka berperan aktif dalam kegiatan Desa atau RT. Ada juga yang menjabat sebagai Ketua RT atau RW. Sehingga jelas peran kader tidak lepas dari peran pemerintahan. Kader Kesehatan di Organisasi 'Aisyiyah mayoritas memegang peran kader di pemerintahan seperti kader Posyandu balita maupun lansia. Mereka karena aktifnya bisa saja merangkap peran menjadi ketua pengajian ibu-ibu 'Aisyiyah atau sekretaris Ranting 'Aisyiyah setempat. Kondisi tersebut menunjukkan bahwa sifat suka rela yang benar adanya ditunjukkan oleh kader kesehatan (Effendi \& Makhfudli, 2009). Kader kesehatan masyarakat adalah laki-laki atau wanita yang dipilih oleh masyarakat dan dilatih untuk menangani masalah-masalah kesehatan perseorangan maupun masyarakat serta untuk bekerja dalam hubungan yang amat dekat dengan tempat- tempat pemberian pelayanan kesehatan (Syafrudin \& Hamidah, 2009). Walaupun seluruh kader Aisyiyah adalah perempuan namun tidak menurunkan semangat mereka unruk bersamasama masyarakat meningkatkan taraf kesehatan.

Kegiatan yang rutin dilakukan di Ranting 'Aisiyah seperti arisan ibu-ibu Ranting, pengajian ibu-ibu, pengajian yang disertai dengan bapakbapak dan tadarus bersama. Bakti sosial juga dilaksanakan dalam rutinitas bulanan atau jika ada bencana baik lokal maupun dari wilayah lain. Bakti sosial ini Ranting melakukan kerjasama dengan beberapa pihak seperti Institusi Kesehatan, mahasiswa PKL bidan Kesehatan, Puskesmas setempat atau Klinik Kesehatan. Kegiatan dari Ranting 'Aisyiyah Umbulharjo, Tegalrejo, jetis Kota maupun Kotagede hampir sama. Hal ini merupakan bentuk kepedulian kader kesehatan baik secara ekonomi, sosial dan kesehatan lingkungan. Kegiatan tersebut juga menjadi bentuk pemberdayaan dalam wacana pembangunan selalu dihubungkan dengan konsep mandiri, partisipasi, jaringankerja, dan keadilan (Depkes $\mathrm{RI}, 2008)$.

Selain kegiatan rutin, kegiatan di bidang kesehatan yang dilakukan dari masing-masing Ranting tidak bisa terpisahkan dari kemasyarakatan dan pemerintahan. Kegiatan Posyandu, kader dari Ranting Umbulharjo, Tegalrejo, Kotagede dan Jetis juga tetap ikut serta. Kader yang berasal dari Tegalrejo juga menyampaikan hal yang sama. Bahwa meraka tetap ikut serta bidang kesehatan seperti kegiatan Posyandu, perekrutan kader atau pengurus baru, melakukan kerjasama dengan atau kegiatan Ketuk pintu TB. Kegiatan ini menjadi andalan dari Ranting Tegalrejo. Namun, 
proses mengambilan data TB tetap melakukan kerjasama dengan Puskesmas atau tim PUS-PK yang dari Puskesmas yang menggandeng kader Posyandu. Kegiatan yang dilakukan oleh kader tersebut sesuai dengan teori yang menyampaikan bahwa peran utama kader kesehatan adalah memikirkan bagaimana cara meningkatkan kesehatan dan kesejahteraan masyarakat (Syafrudin \& Hamidah, 2009).

Kegiatan tersebut sesuai dengan yang disampaikan oleh beberapa partisipan dari Jetis Kota, Kotagede dan Umbulharjo, bahwa para kader bekerjasama dengan instansi pendidikan swasta ('Aisyiyah dan Muhammadiyah) untuk memberikan informasi kesehatan. Misalnya dalam kegiatan PKL (Praktik Kerja Lapangan) mahasiswa diminta untuk memberikan penyuluhan kesehatan kepada kader maupun masyarakat. Penyuluhan ini tidak sekedar undangan untuk mengikuti acara penyuluhan saja, namun biasanya penyuluhan masuk dalam agenda pengajian rutin yang telah berjalan di masyarakat. Selain itu ada pula kegiatan tadarus dan arisan atau pertemuan RT. Informasi-informasi kesehatan terasa penting untuk disisipkan melalui kegiatan tersebut karena akan lebih mudah mengumpulkan massa dan dapat diterima oleh masyarakt pada umumnya. Cara kerja dari kader tersebut sejalan dengan panduan bahwa dalam menjalankan perannya sebagai kader, mereka perlu melakukan kerjasama baik lintas sektor maupun lintas program (Notoatmodjo, 2011).

Kegiatan kader 'Aisyiyah tidak hanya include dalam kegiatan kampung/dusun, namun juga memiliki kegiatan lain yang sudah terbentuk dari
Program Majlis Kesehatan. Kegiatan itu seperti Posyandu Sakinah. Kegiatan ini digunakan sebagai saranan untuk memantau kesehatan dan kesejahteraan lansia. Posyandu ini juga bekerja sama dengan Rumah Sakit PKU Muhammadiyah setempat sebagai bentuk bakti sosial dan pengobatan gratis. Kegiatan inipun juga tidak lepas dari peran serta praktisi pendidikan, untuk memberikan penyuluhan, maupun pemeriksaan sederhana seperti tekanan darah, gula darah, asam urat, dan kolesterol.

Selain pendampingan Lansia, kegiatan lain yang dilakukan oleh kader kesehan Ranting 'Aisyiyah adalah deteksi dini Penyakit Tidak Melular (PTM), pemantauan TB untuk wilayah kota melalui Program Ketuk Pintu TB. Terkait penyakit TB, kader tidak hanya melaksanakan sendiri, namun berada di bawah naungan Puskesmas setempat. Masyarakat yang terdiagnosa oleh kader mengalami tanda dan gejala TB akan dilaporkan ke Puskesmas setempat, sehingga petugas Puskesmas akan melakukan kunjungna rumah dan melakukan terapi. Puskesmas menggandeng kader Posyandu dan kader 'Aisyiyah untuk mendapatkan pelatihan pendampingan konsumsi obat TB. Beberapa kegiatan dan peran kader tersebut tidak lepas dari peran kadder sebagai tangan panjang dari tenaga kesehatan untuk menjalankan program Pemerintah terkait dengan kesehatan. Sebelum kader menjalankan perannya dan melaksanakan berbagai kegiatan pastinya kader mengetahui alasan atau hal yang mendasari kegiatan tersebut. Dari segi ilmu pengetahuan, kader tentunya secara tidak langsung mempelajari ilmu kemasyarakatan, sosiologi dan epidemiologi (Mubarak \& Chayatin, 2019). 
Kegiatan-kegiatan yang murni dilakukan oleh Ranting 'Aisyiyah biasanya didanai oleh pengurus Ranting. Sistem pendanaan ini sifatnya sukarela. Misalnya secara "bergiliran" atau bergantian. Suatu kegitan seperti pengajian biasanya difasilitasi tempat dari salah satu rumah warga atau menggunakan gedung serba guna, serambi masjid dan mushola 'Aaisyiyah.

Konsumsi yang disediakan berasal dari warga dengan sistem 'urunan (bahasa Jawa)". Satu orang menyiapkan minuman, orang lain menyiapkan 1-3 jenis snack. Atau jika ada dana lain bisa pesan snack yang berasala dari produksi setempat. Pendanaan yang selalu menjadi kendala dari Ranting 'Aisyiyah dalam setiap mengadakan acara. Hal ini dikarenakan tidak adanya dana rutin yang berasal dari organisasi. Solusi yang biasa dilakukan oleh Ranting untuk setiap kegiatan besar baik kesehatan maupun di luar kesehatan adalah dengan memohon bantuan dari beberapa pihak. Permohonan bantuan itu seperti dari Ranting menyampaikan surat permohonan bantuan sesuai dengan kebutuhan bantuan dari kegiatan yang di lakukan.

Salah satu usaha yang dilakukan oleh kader 'Aisyiyah adalah melakukan kerjasama rutin dengan pihak institusi kesehatan, pendidikan dan Klinik khusus yang secra suka rela dapat memberikan ilmu, informasi baru dan pemeriksaan gratis. Hal ini dilakukan dalam upaya pemberdayaan masayrakat. Artinya masyarakat tidak diberikan secara instan pelayanan namun membuka pola pikir masyarakat agar mampu menjalankan kehidupannya secara sehat, baik jasmani maupun rohani secara mandiri. Mulai dari individu yang nanti akan dibawa dalam ranah keluarga. Sehingga sesuai dengan program 'Aisyiyah yaitu mewujudkan masayrakat yang Qoriyyah Thoyyibah. Hal inu dapat terbentuk berdasar dari keluarga yang sakinah. Sakinah ini dinyatakan bahagia, ayom ayem dimana mereka secara mandiri dan dengan kesadaran sendiri dapat menjaga, mencegah dan mengobati apabila individu atau keluarga mengalami sakit.

Berdasarkan tinjauan di atas, dapat dikatakan bahwa konsep pemberdayaan masyarakat mencakup community development (pembangunan masyarakat) dan community-based development (pembangunan yang bertumpu pada masyarakat) (Mulyawan, 2016). Community development (pembangunan masyarakat) bagaimana individu, kelompok atau komunitas berusaha mengontrol kehidupan mereka sendiri dan mengusahakan untuk membentuk masa depan sesuai keinginan mereka (Kemenkes RI, 2015). Pemberdayaan masyarakat juga diartikan sebagai upaya yang disengaja untuk memfasilitasi masyarakat lokal dalam merencanakan, memutuskan, dan mengelola sumberdaya lokal yang dimiliki melalui collective action dan networking sehingga pada akhirnya mereka memiliki kemampuan dan kemandirian secara ekonomi, ekologi, dan sosial (Suwarto, 2009). Kondisi ini sesuai dengan tujuan dari kegiatan yang dilaksanakan oleh Kader 'Aisyiyah yang bekerja sama dengan lintas sektor dan lintas program.

Community-based development (pembangunan yang bertumpu pada masyarakat), Gerakan pemberdayaan masyarakat juga merupakan cara untuk menumbuhkan dan mengembangkan norma yang membuat masyarakat mampu untuk berperilaku hidup bersih dan sehat. Strategi ini 
tepatnya ditujukan pada sasaran primer agar berperan serta secara aktif.

\section{Kesimpulan}

Kader di masing-masing Ranting 'Aisyiyah berperan aktif dalam setiap kegiatan. Kegiatan terkait kesehatan yang dilakukan oleh kader 'Aisiyiyah di Ranting 'Aisyiyah adalah pengajian, arisan pengurus Ranting, kajian atau pertemuan rutin warga 'Aisyiyah, Program Ketuk Pintu TB, pendampingan minum obat, Posyandu Lansia Sakinah, dan deteksi dini Penyakit Tidak Menular. Kader 'Aisyiyah melakukan kerjasama dengan Institusi pendidikan baik 'Aisyiyah atau Muhammadiyah untuk memberikan penyuluhan kesehatan, pemeriksaan kesehatan dan pengobatan. Peran kader Kesehatan di Ranting 'Aisyiyah merupakan peran ganda yang dilakukan oleh seorang kader dan semata-mata untuk membantu program pemerintah mewujudkan masyarakat yang sehat secara mandiri.[]

\section{Daftar Pustaka}

Bappeda. (2013). Data Profil Yogyakarta. Diambil dari http://bappeda.jogjaprov.go.id/dataku

Depkes RI. (2008). Buku panduan pelaksanaan program kesehatan untuk menciptakan masyarakat yang sehat. Jakarta: Departemen Kesehatan Nasional.

Dinkes DIY. (n.d.). Profil Kesehatan Provinsi Daerah Istimewa Yogyakarta.

Effendi, F., \& Makhfudli. (2009). Keperawatan kesehatan komunits: Teori dan praktik dalam keperawatan. Jakarta: Salemba Medika.
Fallen, R., \& Dwi, R. B. (2011). Catatan kuliah keperawatan komunitas. Yogyakarta: Nuha Medika.

Hidayat, S. (2002). Metode penelitian perilaku kualittif dan kuantitatif. Bandung: Alfabeta.

Kemenkes RI. (2015). Pedoman pemberdayaan masyarakat dalam penanggulangan krisis kesehatan. Jakarta: Pusat Penaggulangan Krisis Kesehatan Kemenkes RI.

Meilani, N. (2009). Kebidanan komunitas. Yogyakarta: Fitramaya.

Mubarak, W. I., \& Chayatin, N. (2019). Ilmu kesehatan masyarakat: Teori dan aplikasi. Jakarta: Salemba Medika.

Mulyawan, R. (2016). Masyarakat, wilayah dan pembangunan. Bandung: Unpad Press.

Notoatmodjo, S. (2011). Kesehatan masyarakat: IImu dan seni. Jakarta: Rineka Cipta.

Rachmat, R. H. H. (2017). Penguatan upaya kesehatan masyarakat dan pemberdayaan masyarakat bidang kesehatan di Indonesia. Yogyakarta: UGM Press.

Sugiyono. (2012). Statistik untuk penelitian. Bandung: CV Alfa Beta.

Sulaeman, E. S. (2012). Model pemberdayaan masyarakat bidang kesehatan: Studi Program Desa Siaga. Kesmas: National Public Health Journal, 7(4), 186-192. https://doi. org/10.21109/kesmas.v7i4.54.g55

Supardan, I. (2013). Pemberdayaan masyarakat bidang kesehatan. Diambil dari http:// doktergigi-semarang.blogspot.com/2013/ 06/pemberdayaan-masyarakat-dibidangkesehatan.html

Suwarto. (2009). Menggerakkan partisipasi masyarakat. Jakarta: Salemba Empat. 
Ririn Wahyu Hidayati, Nurul Mahmudah

Syafrudin, \& Hamidah. (2009). Kebidanan komunitas. Jakarta: EGC. 